\title{
El último cucurucho
}

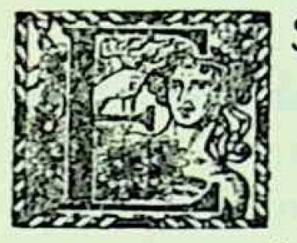

S el último que yo vi o. por lo menos, el último que recuerdo haber visto en aquella lejana época de mi vida; o mejor: el misterio que envolvía a esos trágicos encapuchados, de fúnebre careta y largo bonete de mago, vestigios de una época que ya se disolvia en el tiempo, se desgarró para siempre aquella tarde de otoño, bajo los corredores de la casa campesina que fué de mis abuelos. en la soledad de un Viernes Santo de principios del siglo. Se produjo en mi alma infantil un patético estupor. al darme cuenta que, bajo la lustrosa choleta y la máscara agujereada a la altura de los ojos, era un hombre cualquiera el que se escondía. No eran los enviados de Dios. indignados por el asesinato del hijo del hombre. los tétricos limosneros ante cuya alcancia bendita se abrian las bolsas y se desataban pañuelos: eran pobres diablos disfrazados que. cómicamente. gritaban una salmodia tradicional cuyo origen se perdía en los oscuros tiempos coloniales.

Recuerdo ese instante de mi niñez como si fuera ayer. tan vivamente se proyecta su imagen en mi memoria: era yo un chico de siete años y vivia en el campo. en casa de mi tío Bernardo: hacía un año que había quedado huérfano: y mi tío. hermano mayor de mi madre, que no tuvo hijos. se habia hecho cargo de mi. Mi tio Bernardo era un genuino chileno de principios del siglo diecinueve: alto. fornido. de cuadrados hombros, de nobles rasgos varoniles; una barba rubia. espolvoreada de gris. enmarcaba aquella cabeza tipica: a pesar de sus sesenta años era ágil su paso y su mirada de retadora fijeza: el impelu del conquistador del cual descendiamos latia en el agua clara de sus ojos severos. Aunque de palabra recia y ademanes impacientes, era de una gran bondad. Tenia el apego de los campesinos a lo cómico, a los chascarros de la tierra salpimentados de gruesa. sal. Se complacía en bromas infantiles que irritaban a mi tia Petronila. una señorona de aldea. espetada y beatísima.

Lo veo aún con su hermoso poncho de vicuña. de flecos tan largos que besaban las puntas de sus recias botas de cuero: o montado en su yegua baya de curva anca partida. atravesar los potreros en las mañanas de verano. Ejemplar de una raza ya desaparecida desgraciadamente. la heredera de los que pelearon el año 10 contra los españoles. Si aquellos hombres se levantasen de sus tumbas. 
se imaginarian que sus descendientes, entecos y desmoralizados, son otros invasores a los que habría que combatir y arrojar de nuevo de la tierra.

Mi tio administraba su heredad, la misma encomienda de su antecesor del siglo XVII, a la manera patriarcal; sus inquilinos, hijos de indios y blancos. le querian y le respetaban; no habia conflicto entre patrón y labriegos: éstos no se sentian cohibidos en su presencia: salvo uno: el maestro José Morales, el herrero, un viejo iluso que tenía su fragua en un costado del enorme caserón de la hacienda. El maestro era el tipo caracteristico de la mezcla de indio y castellano; del abuelo español no conservaba sino unos ojos grises, desconfiados y tristones; brillaban como barnizados sus pómulos puntiagudos, tan salientes que habian impreso al rostro una cómica mueca de temor; tenía el miedo supersticioso del indio por lo sobrenatural, por lo misterioso: y al trocar, a través del siglo. sus idolos de madera por el dios de los peninsulares. en nada había cambiado su pintoresco panteísmo de raza primitiva.

Las ánimas le habian hecho revelaciones de entierros que se manifestaban en forma misteriosa; ya era un fraile mercedario que se aparecía bajo la copa de un maitén, o lucecillas que se perseguian a media noche en las cercanías de la capillita de Calleuque, media derruida ya y en cuyas podridas vigas colgaban las golondrinas, en la primavera, sus nidos bulliciosos.

Mi tío intervino en el noctámbulo ensueño del herrero al aparecer cierto pía una excavación profunda, al pie del maitén. que dejaba al descubierto las viejas raíces del árbol. En un principio bromeó con él; rióse de sus consejas e ilusiones; pero al advertir la convicción profunda del campesino. la fe de poseído que iluminaba sus ojillos grises y daba calor a su relato, yo vi que una chispa de codicia prendió en la franca claridad de sus pupilas; creía, como todos, en estas revelaciones de ultratumba; eran enormes tinajones llenos hasta la boca de relucientes onzas o arcones que, enterrados bajo el piso de la capilla. contenian valiosos copones de oro y pedrerías de iglesia. Su tono cambió, entonces: cuchichearon ambos animadamente y esa tarde mi tío acompañó al herrero hasta el camino. Poco tiempo después eran enemigos, sin que yo me diese cuenta de la causa.

El maestro no se alejó, sin embargo. del fundo: pero mi tio no desperdiciaba ocasión para zaherirlo, aunque fuese sólo por unas herraduras que no se habian colocado con la prisa que él exigía. ¿Talvez el maestro se negó a darle participación en los tesoros que le habian de enriquecer y él esperaba, por estar los entierros en su propiedad, que alguna vez se decidiese?

Yo le oí a la Verónica, la vieja cocinera de la casa, una versión más exacta:

-El maestro José no puee participarle naa. porque el patrón Bernardo lo hace por coicia... El es rico. La coicia corrió el entierro y cambió el oro en canillas de ave... en pieiras de río.

Nunca mi tío habló con nadie en la casa de esos fabulosos hallazgos. ni parecia creer en ellos; al contrario, burlábase de la ingenuidad de los huasos; y mi tia que, como buena chilena, no dudaba un punto de la existencia de esos 
entierros, sobre los cuales se mataba al indio esclavo que habia cavado el hoyo, para que no se divulgase el secreto, mirábalo con asombro: se alejaba indignada a rezar para que el descubrimiento de su marido, teñido ya de siútico pipiolismo. no atrajese la cólera de Dios sobre la casa.

Al atardecer, el maestro José solía atravesar el patio hacia el camino, bajos los ojos, sin mirar nunca a los corredores, donde siempre se veía la alta silueta del hacendado envuelta en su poncho de vicuña: mi tío seguialo hasta que doblaba la reja con una sonrisa irónica. No hubo desde entonces más excavaciones al pie del maitén del mercedario, como empezaron a llamarlo en el campo. El herrero debió recibir nuevas revelaciones que esta vez no salieron a luz, ni volaron por las ranchos. iAquellas buenas ánimas, talvez las de los indios muertos sobre los arcones o tinajas, avisaban al hombre elegido hacia donde había corrido el entierro la codicia del patrón!

Nada ocurrió en aquella escondida tierra, que bajas colinas encerraban, hasta la tarde de oro de la Semana Santa que nunca olvidaré.

El oro rojizo del otoño había patinado los campos; en el aire quieto pesaba el sopor de las tierras cansadas, el sabroso aroma de lo que ya ha madurado y se deshace lentamente para volver a la tierra de donde nació: de la pequeña bodega, de podrido tejado, cerca de la casa, llegaba un olor azucarado de mostos nuevos. de ásperas fermentaciones; las cañas rotas de un maizal, ya cosechado. semejaban cruces sin aspas de un cementerio de aldea y en el crepúsculo declinante, la alameda que, en recta perspectiva se perdía en la llanura, era como una hoguera de altas llamas de oro que se extinguiese lentamente: los tordos y jilgueros, en bandadas bulliciosas, no se apartaban de los despojos de la viña.

El campo estaba desierto; todo el inquilinaje. con sus ponchos pintorescos y sus violentos bonetes rojos los hombres y las mujeres envueltas en sus rebozos de castilla. desfiló hacia la aldea desde el Lúnes por la mañana, a las ceremonias de Semana Santa; era aquel un verdadero día de luto. como si realmente detrás de alguna colina se crucificase a Cristo y se temiese la represalia de Dios. Interrumpianse por completo las labores rústicas: frente a la casa brillaba, a los rayos del sol. la reja de un arado, sobre el surco del barbecho interrumpido el Sábado en la tarde: y un buey rojizo, de largas astas torcidas. en la soledad de un rastrojo, entre las cañas amarillas, tenía en su inmovilidad un matiz de idilica melancolía.

Caía la tarde; el lomo lejano de las cordilleras, impreso en un cielo desleído de otoño, refulgía como una brasa viva. En el viejo banco. pegado a la pared desde tiempo inmemorial, estábamos mi tio y yo. Durante el día entero y los anteriores no me había apartado de su lado; lo seguia como un perrito a todas partes. Los misteriosos colrades del Santo Sepulcro que dibujaban en el camino su espantable silueta, con el crucifijo enorme coronado por un velón de cera y el sonajeo de sus alcancias llenas de reales y cuartillos: su fantástico grito de alma en pena: Para el Santo entierro de Cristo y Soledad de Maria. que hacía aullar a los perros y ocultarse a los muchachos tras las basquinas de sus madres, habian sumido mi alma infantil en un horror angustioso. iRidículo perso- 
naje de épocas lejanas en que yo corporizaba las ánimas vagabundas, el arrastre de cadenas en las casas embrujadas y las candelillas de los cementerios de que hablaban las consejas de nuestra cocinera! $\mathrm{Mi}$ tio era otra cosa: era el único que miraba risueñamente el bonete puntiagudo y la careta terrorifica: pues los campesinos, apenas oian su grito fúnebre cerca de sus ranchos. en los que penetraban sin llamar, santiguábanse devotamente y sus dedos comenzaban a desenvolver precipitadamente el policromo pañuelo; y en la alcancia abollada iban cayendo los reales y cuartillos de tosco sello de la época. Mi tio divertíase a veces con $\mathrm{mi}$ terror; reiase, cuando mis manecitas se aferraban a los flecos de su poncho y su mirada azul dejaba caer su bondad protectora desde lo alto de su cabeza canosa. A un descuido mío, escondiase tras un árbol y me dejaba solo en medio del campo. Cuando veía dibujarse en mi cara la mueca de un puchero, aparecia repentinamente y mirándome de reojo, sonreía al ver deshacerse como en una fuente limpida, las arrugas del llanto. Ponía su mano sobre mi cabeza y decía:

- Hay que ser valiente, amigazo.

Me cogia cariñosamente de la mano y avanzábamos hacia la casa. Nunca olvidaré el calor de esta manaza áspera de agricultor que suavemente encerraba en su tibio seno mi manecita inocente: era un fluído misterioso el que se trasvasaba a mi sangre, reconfortante como un añejo vino de la tierra; quizá la voz de la raza que venía a despertar en mi pecho infantil, a través de los siglos, el ansia de acometer altas empresas.

Hacía largo rato que mi tio no hablaba: chupaba con fruición su cigarrillo de hoja de maiz que había preparado poco antes cuidadosamente; oíase el rezongo monótono de los rezos de la servidumbre en el oratorio; una rálaga de aire trajo trinos entrecortados de pájaros y arrastre rumoroso de hojas secas en la alameda. Cerca del corredor dormitaban los cuatro enormes perros de mi tio. que tenian fama de bravos en el campo; perros deformes, de anchas cabezas y colores indefinibles, de raza inclasificable como los inquilinos de la región; y como éstos, agresivos y mal humorados. De pronto. los perros gruñeron; uno, cuyo ojo derecho rodeaba un círculo blanquecino, el .Malacaras, mostró su hocico armado de agudos colmillos amarillentos y corrió hacia el camino: los demás lo siguieron. Sólo ahora me doy cuenta de que este movimiento instintivo de los perros se reflejó también en los ojos de mi tio: también él se puso de pie y avanzó hacia el patio. Sin embargo. nada se veia aun. Súbitamente el terror paralizó mis movimientos: mis manos crispadas se aferraron al poncho de mi tío. Montado en un caballejo mulato de lacio belfo y ancas puntiagudas, caminaba hacia el corredor un cucurucho de bonete desmesurado y enlutada careta; apoyaba la alcancia en el borrén de su avío y en su mano derecha un tosco crucifijo color de madera parecia la rama de un árbol seco. Avanzaba lentamente, seguro de su predominio sobre la devota gente de los campos. Los perros ladraban enfurecidos, pero sin acercarse mucho.

Entonces se produjo el desastre. Mi tio lanzó un grito metálico, primitivo. que tenía de ladrido furioso y de voz humana: sus labios se torcieron y una llama feroz apareció en sus ojos; era un alarido de combate, huella ancestral que 
reaparecia en esos momentos. Los perros. enardecidos con la voz de su amo, se lanzaron sobre el cucurucho, cuando éste, seguro de su poder. lanzaba su grito agorero: Para el Santo entierro de Cristo y Soledad de María.

Luego. no ví sino perros que se pegaban furiosos a las patas del caballo, trozos de choleta negra que volaban por el aire. el galope del caballejo espantado, abierta la cola como la cresta de un papagayo y el brazo del jinete que manejaba el crucifijo, a modo de palo: vi desprenderse el cucurucho del tronco del hombre; y la cabeza oscura de un huaso se reveló a mis ojos. Mi terror murió para siempre. Se produjo en mi ánimo un cómico estupor. semejante al que experimenté una tarde al ver, bajo las sotanas del señor Cura que bajaba de una carreta, unos pantalones de huaso idénticos a los de mi tio.

Mi tía y las sirvientes aparecieron en la puerta del corredor; el espanto inmovilizaba sus caras oscuras. Los perros volvían, relamiéndose el hocico: uno de ellos traía un trozo de choleta entre los dientes; se acercaron a nosotros con un no se qué satisfecha vanidad en el meneo de su cola; y parecieron avergonzados cuando mi tía los alejó con gritos coléricos: luego. furiosa, se encaró con mi tio.

- Hombre hereje, pipiolo descreido no más. Faltarle el respeto a la religión el día que velan el señor! iQué desgracia caerá sobre esta casa excomulgada!

Mi tío respondió bromeando. con ese tono de huaso socarrón que empleaba en las cosas que no tenian importancia:

-No fuí yo, ña Petra. fueron los perros; no pude sujetar a estos leones. mire... Se fueron di hacha....

Mi tía replicó con más cólera aún:

- Pero si te ví que los animastes. iComo si no te conociera!, pero mi tio cortó brutalmente su imprecación con un grito ronco, que me recordó el alarido de poco antes; el grito omnipotente del amo:

- Tu no has oído nada... ¿Entiendes? ándate pa tu pieza.

Y la viejecita. santiguándose, inclinó la cabeza y se retiró hacia el pasadizo seguida de los sirvientes. que atemorizados, se atropellaban en la puerta.

$\mathrm{Mi}$ tío se sentó entonces en el viejo banco de roble; y yo a su lado. No hablaba: pero sobre el oro gris de sus barbas. la sonrisa parecia revoletear como una mariposilla loca y obstinada.

La casa se anegaba poco a poco en las olas de sombra gris que venían de todos los rincones del campo. Los viejos pilares del corredor blanqueaban en la penumbra. rígidos, espectrales. con no se qué tristeza indefinible: habia en ellos un cansancio resignado que siempre me hizo meditar con angustia: me recordaba a los inquilinos que, sin moverse nunca de sus ranchos de paja y barro. soportaban sobre sus espaldas la esclavitud de un trabajo de siglos; aquel viejo techo. por entre cuyos aleros brotaban murciélagos semejantes a puñados de sombra deshecha, dejaba caer sobre ellos todo el peso de sus maderas. Un criado colgó un candil frente a nosotros: informes masas de sombras parecieron huir hacia el campo apenas la llama comenzó a lamer la noche con temblorosos brochazos. 
En mi cerebro clavábase como una obsesión el deseo de ir en busca del cucurucho que había visto rodar del camino, desde la cabeza del huaso.

En ese instante un hombre se acercó hasta el filo del corredor.

-Patrón, dijo, ei lo buscan d'ionde el sudelegado...

Mi tio respondió tranquilamente:

-Dile que pase...

A los pocos segundos apareció un soldado, uno de esos soldados de policía rural, medio campesino, medio militar, cuyas espuelas tintineaban a cada uno de sus pasos.

-E parte e on Salustio que vaya altirito p'al juzgado, con el niño que esfaba en el corredor....

- ¿Qué es?. preguntó mi tio con el tono del que nada tiene que reprocharse.

-No sé, on Bernardo, contestó el hombre con desgano, parece que se han querellado... Evitaba respetuosamente el nombre del rico hacendado.

Replicó mi tío con agrio encono:

- ¿Y no pudo dejarlo para mañana ese... mi compadre?. y agregó arrepentido. Dile que ya voy.

En medio de su protestas se ponía el sombrero y pedía el mío a grandes voces coléricas: nos encontramos, de pronto, en el camino, bajo la noche otoñal. hacia la vivienda del subdelegado, a una legua del fundo. Los grillos llenaban la fresca noche con su chirrido áspero, oliente a humedad, a tierra mojada; una lechuza lanzó desde la masa negra de un árbol su silbido en sordina. Mi tío avanzaba a largas zancadas, visiblemente preocupado. Cuando su compadre lo molestaba, era de seguro por algo grave.

A pesar de su entereza, su manaza oscura, del color de la buena tierra, de largos dedos torpes, que recordaban las patas entumidas de las arañas de los cerros en invierno, tenía un ligero temblor. Yo debía correr para ponerme a su lado. Se detuvo en la mitad del camino:

-Estás cansado, mocosillo?, habló cariñoso.

- No. tata, le contesté, que por este nombre familiar le llamaba a menudo.

Llegamos frente a la casa del subdelegado de la comuna: era un caserón idéntico al nuestro, pero más reducido: tenía esa afinidad de las viviendas campesinas. esa fisonomía austera de corredores que las hace parecerse como los rasgos de los huasos.

Montones de papas rojizas, de la última cosecha. llegaban hasta la viguetería, gris de telarañas, cargadas de tierra; en el patio, unos labriegos quemaban la paja de los porotos cosechados: y el rojo chispeo de las llamas, en medio de la noche, tenía no sé qué dulce reconfortamiento. El soldado que fué a buscarnos había llegado ya; y él mismo nos guiaba hacia la oficinita del juzgado rural, en el otro estremo del corredor. Jamás he olvidado aquel rincón frío, de sueltos ladrillos, con la viguetería desnuda, decorada por las telarañas; las sillas de paja. pegadas a la pared: y un brasero donde hervia una tetera con suave murmujeo. La luz humosa de un chonchón, con su llama redonda terminada en una aguda 
lámina oscura, hacia bailar las caras de los que se habian reunido alli, una noche de Viernes Santo, por un motivo oscuramente trágico que me llenaba de torturador presentimiento. ¿Qué intentarían contra mi tio? Su manaza áspera no se desprendía de la mía, del niño que estaba en el corredor, que habia adquirido repentinamente una personalidad inusitada.

Mi tío saludó, con su voz de pausado timbre, ligeramente socarrona;

- Muy buenas noches, señor compadre!

- Buenas noches. contestó éste, sin moverse de su sillón de brazos y sin invitarnos a tomar asiento. Era un hombre flaco, de mejillas hundidas y larga nariz picuda; una barba raquítica, medio gris, salía sin fuerza de su mandibulas: su voz era ronca. mandona, antipática:

- Este hombre lo acusa de desacato a la religión, de herejía...

Nuestros ojos y los del soldado que permanecia en la puerta, se dirigieron instintivamente hacia el rincón sombrío del cuarto, que nos señaló. de un modo vago. la mirada del Juez; allí habia un hombre sentado. en actitud abatida; no se le veía el rostro, porque la llama dejaba el ángulo envuello en tinieblas; pero una rálaga de aire alargó la lengüecilla del candil; y con asombro reconocí al maestro herrero que no veía desde el comienzo de la Semana Santa; sus hombros estaban envueltos con los restos de la sotana de los colrades del Santo Sepulcro: en su mano brillaba aún el paño agujereado de la careta. Una resignación de vencido, de perro apaleado encogía su figura. Con grandes precauciones, para no encontrarme con la mirada de mi tio, empecé a girar mi cabeza hacia él: su noble rostro no se conmovia; una gran serenidad, una hidalga entereza lo hacía casi duro; sólo que... alrededor de las barbas, yo únicamente, por el sortilegio del cariño, advertía la sonrisita socarrona. movible como una mariposilla loca y obstinada.

Resonó la voz ronca del Juez:

-Este hombre lo acusa de abuso de confianza, y dice que le tiene ley por lo de los entierros: y le animó los perros de pura mala intención, rompiéndole el traje bendecido en la iglesia... Yo lo voy a mandar con parte al juzgado. (su voz se hizo enérgica). por este desacato... si no se arreglan las partes de otro modo... (su voz se apaciguó).

Los ojos húmedos del maestro herrero se atrevieron ahora a levantarse, deprimidos por triste abatimiento.

Mi tío habló serenamente:

- ¿Cómo podía conocerlo, estando vestido de cucurucho? Yo no le animé los perros; se asustaron estos tigres cuando vieron el capirote negro. A cualquiera se la doy, señor...

Había en su voz un matiz irónico, apenas perceptible; pero no era bastante a ahogar el sollczo que se incubaba en $\mathrm{mi}$ pecho que. como una impaciente burbuja de aire, quería salir a la superficie a toda costa.

El juez me interrogó:

- Tú estabas en el corredor... ¿es cierto todo esto?

La mano de mi tio me dió oportunamente un ligero apretón de alerta: 
-Si, balbuceé débilmente...

- Entonces Ud. se allana a pagar los daños?. preguntó, el compadre, conciliadoramente.

- No deseo otra cosa. contestó mi tio Bernardo con el tonillo burlón que esta vez me pareció la misma sonrisa que se hacia palabra articulada.

El juez se dirigió al maestro herrero. El soldado, que se apoyaba en el marco de la puerta, se enderezó con un suspiro de alivio.

- ¿Cuánto pedis?

Lacónicamente, con voz opaca, murmuró, especificando, el maestro:

- El cucurucho, 7 1/2; el traje, 8 reales.

$\mathrm{Y}$ todos miramos a mi tío que, con un gesto de gran señor. levantaba pausadamente una punta de su pesado poncho de vicuña; y de la bolsa de cuero donde se llevaban las monedas en aquella época, semejante a una escarcela medioeval, extraía una brillante onza que tintineó argentinamente al dejarla caer en la mesa de roble; hipnóticamente se fijaron en el reluciente disco de oro los ojos del cucurucho: talvez pasaban por su imaginación de iluso, tinajones repletos de onzas que la codicia de los patrones cambió en huesos de aves y en canillas de indios.

Sin despedirse, sin esperar el resto de la onza, mi tio tiró de mi mano y salimos a la carretera.

La hoguera consumiase en el patio, la sombra húmeda ahogaba los rojos tizones que habian abandonado los labriegos y en la soledad del camino. la noche campesina dejó oir sus mil voces peculiares: en un charco gargarizó una rana ronca, como un bajo que ensaya por juego las notas más graves de su registro: clarineó un tréguil durante algunos segundos; más tarde, en alas del viento nocturno. llegó el traqueteo de la carraca en la iglesia de la aldea.

Yo me sentía alegre, liviano; mis ideas eran mil alitas diminutas y frágiles que me desprendian de la tierra; mi mano debió llevar esta vibración milagrosa hacia el corazón de mi tio, porque yo notaba la afectuosa presión de la suya; al pasar un esterillo salté tan ágilmente, que mi tío bromeó:

- ¿Quiere volar el pajarito?

Tal fué el último cucurucho que yo vi: o por lo menos, el último que recuerdo haber visto en aquella lejana época de mi vida; o quizá: el misterio que envolvía a esos trágicos encapuchados, de lúnebre careta y largo bonete de mago. vestigios de una época que ya se disolvia en el tiempo, se desgarró para siempre en aquella tarde de otoño. bajo los corredores de la casa campesina que fué de mis abuelos. en la soledad de un Viernes Santo de principios del siglo.

MARIANO LATORRE, 